\title{
Aprendre a ensenyar a escriure: un exemple de plantejament de tasques d'escriptura en la formació de docents de llengua ${ }^{1}$
}

\author{
Mariona Casas i Deseuras \\ Universitat de Vic-Universitat Central de Catalunya (UVic-UCC) \\ Grup de Recerca en Educació, Llenguatge i Literatura (GRELL) \\ ORCID: orcid.org/0000-0002-3992-5540 \\ mariona.casas@uvic.cat
}

Rebut: 20 de maig del 2020

Acceptat: 17 de setembre del 2020

\section{Resum}

Escriure és una activitat complexa. Consegüentment, també és complex el procés d'ensenyament-aprenentatge de la composició escrita i, més encara, en segones llengües. La recerca ens aporta evidències sobre les dificultats amb què topen els aprenents a l'hora d'escriure, per una banda, i les dificultats que manifesten els docents a l'hora d'acompanyar-los, per l'altra. El repte, doncs, consisteix a reconèixer els obstacles que apareixen durant el procés d'escriptura i a saber fer emergir les estratègies necessàries per superar-los. En aquest marc, l'article presenta algunes idees clau sobre la didàctica de l'escriptura des d'un vessant teoricopràctic, a partir de l'experiència en la formació de docents de llengua. El dispositiu didàctic que es mostra se centra en el plantejament de tasques per aprendre a escriure i aporta reflexions dels futurs ensenyants a l'entorn de la didàctica de l'escriptura. En conclusió, l'article sosté que docents i aprenents participen del mateix objectiu quan es tracta d'ensenyar i aprendre a escriure, i aquesta assumpció és un convit a repensar el paper d'ambdós agents davant d'aquest repte.

\section{Paraules clau}

Didàctica de l'escriptura, ensenyament i aprenentatge de llengües, escriptura en L2, formació del professorat, situació retòrica

\begin{abstract}
Writing is a complex activity. Consequently, the process of teaching and learning written composition, especially in second languages, is also complex. This research provides evidence, on the one hand, of the difficulties that learners face when writing, and, on the other, of the difficulties that teachers have when guiding their students. The challenge is thus to recognize the obstacles that arise during the writing process and to know how to bring out the strategies that are needed to overcome these obstacles. In this context, the paper presents some key ideas about teaching how to write from both a theoretical and a practical points of view, based on the experiences gained when training language teachers. The didactic device that is shown in this paper focuses on creating tasks in order to teach how to write and provides reflections for future teachers in the environment of the didactics of writing. In conclusion, the article argues that teachers and learners share the same goal when it comes to teaching and learning to write, and this assumption is an invitation to rethink the role of both agents in the face of this challenge.
\end{abstract}

\section{Key words}

Didactics of writing, language teaching and learning, L2 writing, rhetorical situation, teacher training

1 Aquest article està basat en la ponència titulada Com podem ajudar a aprendre a escriure (millor)? Establint ponts entre recerca i pràctiques docents a l'entorn de la didàctica de l'escriptura, que l'autora va presentar a les Primeres Jornades Internacionals de Didàctica del Valencià com a L2 el 21/09/19 a València, organitzades per SERCLE i el CEFIRE. Al llarg d'aquest document s'usa el masculí genèric per referir-se a docents i aprenents tant homes com dones. 


\section{La complexitat de l'escriptura}

L'escriptura és una activitat complexa. Aquesta afirmació, amb la qual qualsevol docent segurament estaria d'acord, no és només patrimoni dels ensenyants de llengües, sinó també dels professionals de la paraula escrita, és a dir, dels escriptors. Els qui es dediquen a escriure i que, per tant, fan d'aquesta activitat la seva professió, reconeixen com de difícil és l'ofici que han escollit. Josep Pla, per exemple, s'hi referia en aquests termes:

És sempre més assequible i fàcil escriure coses confuses i enrevessades que escriure en una llengua intel-ligible i normal. Si la confusió prové del tema complicat, s'ha de veure si el tema existeix realment o és una pura il.lusió de l'esperit (...). Si la qüestió prové de l'estil, la cosa és més intencionada i maliciosa (Pla, 1979, p. 242).

I un altre prolífic escriptor, Josep M. Espinàs, comparteix aquesta reflexió personal sobre el fet d'escriure:

No veig pas res, quan escric. Més encara: no hi ha res -només la màquina i el paper que vaig omplint- fora del meu cervell (...). Aquesta és la humilitat -i també la duresa- de l'ofici d'escriure: que posa a prova allò que hem pensat (Espinàs, 2013, p.15).

En aquest segon fragment, Espinàs revela una característica fonamental de l'escriptura: el seu component epistèmic. Certament, l'activitat d'escriure ens confronta amb el nostre pensament, en el sentit que no només genera coneixement, sinó que ajuda a organitzar-lo a mesura que elaborem nous significats (Carlino, 2004a). Així doncs, no és només una activitat cognitiva, sinó també -i sobretot- metacognitiva: podríem dir que quan plasmem les nostres idees per escrit, anem escrivint allò que pensem però, alhora, pensem i prenem decisions sobre allò que anem escrivint: "A writer in the act is a thinker on a full-time cognitive overload" (Flower i Hayes 1980: p. 33).

L'escriptura és, a més, una activitat instrumental (Camps 2004), perquè permet fixar per escrit el coneixement i l'opinió que l'escriptor té respecte d'un tema. En aquest sentit, també cal reivindicar la lectura, una activitat igualment complexa i amb un alt component cognitiu (Solé 2012), que està interrelacionada amb la composició escrita (Shanahan 2019) i que permet al lector accedir a aquest coneixement escrit. I una altra característica de l'escriptura, compartida també amb la lectura, és la seva dimensió social i dialògica. Tot i que l'escriptura sol ser un acte solitari, escrivim perquè ens llegeixin i aquest diàleg entre escriptor i lectors esdevé un poderós recurs de participació en la comunitat. La llengua escrita és, doncs, un capital social i cultural de primer ordre en la nostra societat.

L'escriptura, però, és l'habilitat lingüística menys dominada pels usuaris de la llengua. Segons la darrera Enquesta d'Usos Lingüístics de la Població de Catalunya (EULP) de l'any 2018 (DGPL 2019), el 94,4\% dels enquestats (majors de 16 anys) entén el català, el 81,2\% el sap parlar, el 85,5\% el sap llegir i només el 65,3\% el sap escriure. Respecte a l'anterior onada (any 2013), el 2018 el percentatge dels enquestats que manifesten saber escriure creix en 5 punts, però el domini d'aquesta habilitat continua essent més baix que el de les altres tres habilitats (entendre, parlar i llegir). L'EULP també recull l'autovaloració sobre els coneixements de català de la població enquestada. En totes les habilitats, l'autovaloració és més baixa que el coneixement i, en el cas concret de l'escriptura, els enquestats s'autovaloren amb un 5,9. De manera similar, si consultem les dades demolingüístiques del País Valencià (Mas 2018), en aquest cas l'enquesta del 2015 del Servei d'Investigació i Estudis Sociolingüístics, l'escriptura també està per sota de les altres habilitats. El 2015, el coneixement declaratiu de l'escriptura era del 34,7\%. Així doncs, partim de la premissa que l'escriptura és una competència complexa, en la qual conflueixen components d'índole diversa. Consegüentment, la primera implicació didàctica és que el procés d'ensenyament-aprenentatge de la composició escrita és, també, complex. I la segona és que, atesa aquesta complexitat, cal atendre l'ensenyament-aprenentatge de l'escriptura amb estratègies diverses en qualsevol etapa educativa, inclosa l'edat adulta. 
En aquest article es comparteixen algunes idees clau sobre la didàctica de l'escriptura i es confronten a l'experiència portada a terme en una formació postuniversitària de docents de llengua, concretament en el Màster d'Ensenyament del Català com a L1 i L2 (Universitat de Barcelona - Universitat de Vic - Universitat Autònoma de Barcelona). Al següent apartat es presenta un marc teòric basat en l'escriptura en segones llengües i en l'ensenyament-aprenentatge de l'escriptura en general (apartat 2) i, en les seccions successives, es desplega la part pràctica de l'article, que es concreta en tres apartats: les representacions que tant futurs docents com aprenents tenen sobre el fet d'ensenyar i aprendre a escriure (apartat 3); un exemple de dispositiu didàctic basat en la situació retòrica (apartat 4) i les reflexions dels futurs docents sobre el plantejament de tasques d'escriptura (apartat 5). L'article es tanca amb unes conclusions que sistematitzen les evidències i reflexions presentades al llarg de l'article (apartat 6).

\section{L'escriptura en segones llengües i l'ensenyament-aprenentatge de la composició escrita}

L'ensenyament de segones llengües en l'etapa adulta (o, si més no, més enllà de l'educació obligatòria) presenta unes singularitats que no es poden obviar a l'hora de plantejar com ajudar els nostres alumnes a aprendre a escriure. Una d'aquestes especificitats té a veure amb el fet que qui aprèn una llengua nova essent adult ja disposa d'un repertori lingüístic, més o menys sòlid, que sol incloure el desenvolupament de la competència escrita (almenys) en la seva primera llengua. En aquest apartat es presenten, sintèticament, els principis bàsics de l'escriptura en segones llengües (Guasch 2001, Kroll 2003), tant des de la perspectiva cognitiva (Silva 1990, Krapels 1990) com sociocultural (Schneuwly 1988, Olson 1995).

Quan algú escriu en una llengua que no és la seva primera llengua (L1) s'estableix una simbiosi entre, per una banda, les seves capacitats cognitives (interlingüístiques) i, per l'altra, els usos lingüístics (inserits en un context retòric determinat). Partint de la hipòtesi d'interdependència lingüística (Cummins 1979 i 2005), cal interrogar-nos fins a quin punt l'usuari domina, en la seva L1, les fórmules d'organització textual i el constructe gènere, per tal que pugui transferir aquest coneixement a la llengua meta en la qual escriu (Bazerman 2009, Bronckart 2008; Dolz i Abouzaid 2015, Kroll 2003, Navarro 2019). No és l'objectiu d'aquest article aprofundir en les recerques sobre l'escriptura en segones llengües (L2), però des del punt de vista didàctic, interessa posar el focus en les variables relacionades amb la transferència d'habilitats (Guasch 2001), les quals, a grans trets, parteixen de les dues premisses següents: a) l'usuari que té dificultats en l'escriptura en L2 també en sol tenir en l'escriptura en L1 i b) Les estratègies que són útils per a l'ensenyament de l'escriptura en L1 també ho són per a l'escriptura en L2 (Krapels 1990). Així doncs, les dues grans variables que caldria tenir en compte quan escrivim en una segona llengua són, per una banda, el grau de coneixement de la L2, que aporta qualitat lingüística a l'escrit, i, per l'altra, l'habilitat d'escriptura en la L1, és a dir, els coneixements sobre l'escriptura i sobre el món desenvolupats en la L1, que són els que aporten qualitat en l'organització del text.

D'acord amb Guasch (2001), un baix coneixement de la L2 influeix tant en aspectes cognitius com d'ús lingüístic: "No posseir un nivell alt d'automatització en l'ús de la L2 condiciona tots els mecanismes cognitius lligats al processament de la informació (...) i no tenir-ne un coneixement semàntic i morfosintàctic desenvolupat limita les possibilitats d'expressió" (p. 46). Això és així perquè quan escrivim, l'ús automatitzat del codi ens permet atendre altres aspectes que participen en el procés d'escriptura. En canvi, la manca d'automatització provoca que l'usuari hagi de resoldre dificultats vinculades al codi i, per tant, no pugui prestar (prou) atenció a les idees i a la manera com les concreta per escrit, decisions que tenen a veure, sobretot, amb aspectes cognitius més que no pas lingüístics. En aquest sentit, pot passar que l'escriptor expert en L1 retrocedeixi cap a comportaments més propis d'usuaris 
no experts quan escriu en L2. És a dir, que si vol mantenir un nivell d'exigència alt, haurà de fer un esforç per afrontar noves dificultats. Constatem, doncs, que l'escriptura en L2 requereix una intervenció didàctica específica, que complementa, enriqueix i retroalimenta l'ensenyament-aprenentatge de l'escriptura en primeres llengües.

Així, en aquest procés d'ensenyar i aprendre a escriure, cal tenir present que el docent esdevé una peça clau (Graham i Harris 2016). El repte consisteix a saber acompanyar l'aprenent al llarg d'aquest procés i, per fer-ho, caldria rescatar els models cognitius d'Scardamalia i Bereiter (1992). En d'altres paraules, hauríem d'ajudar els aprenents a passar del model de "dir el coneixement", és a dir, d'abocar les idees a raig al full de paper, al model de "transformar el coneixement", o sigui, transfigurar i reformular les idees per tal que s'ajustin al context retòric i que estiguin al servei del lector, no de l'escriptor (Carlino, 2004a). La perspectiva docent també hauria d'atendre les tres fases del procés d'escriptura (planificació, textualització i revisió) plantejades per Hayes i Flower (1981) fa quasi quatre dècades, i que les recerques més recents sobre l'ensenyament de la composició escrita s'han ocupat de desenvolupar (Bazerman 2016; Camps, Fontich i Milian en premsa; Castelló 2014; Dolz i Abouzaid 2015; Graham, MacArthur i Herbert 2019; Klein i Boscolo 2016)².

Tot i que les tres fases del procés d'escriptura són recursives, l'interès didàctic de l'aportació de Hayes i Flower rau en la seqüenciació d'aquestes operacions i en el disseny de propostes que posin el focus en l'ensenyament-aprenentatge de cada fase. Diversos treballs (Camps 2003 i 2017; García i Fidalgo 2003; Graham i Harris 2016; Milian 2011) també indiquen que cal promoure pràctiques freqüents i diversificades d'escriptura a l'aula, plantejar consignes que representin un repte cognitiu per a l'aprenent, exposar-lo a models diferents de composició escrita, fomentar actituds positives envers l'activitat d'escriure, plantejar activitats d'escriptura en col-laboració i d'interacció a l'aula, etc. No es tracta de receptes que es puguin aplicar automàticament a l'aula, sinó d'estratègies, recursos i dispositius didàctics que han de servir per aconseguir progressivament l'autonomia de l'aprenent. Si al principi de l'article esmentàvem que l'escriptura és un procés complex, fins i tot per a qui s'hi dedica professionalment, ara convé reflexionar sobre com gestionar la complexitat del seu ensenyament-aprenentatge. L'escriptor i professor Joan Solà ho expressava de manera exquisida en una columna del diari Avui el 19 de febrer de 1998. Amb la claredat didàctica que el caracteritzava, hi explica el procés d'elaboració d'un article en aquesta secció del diari i il.lustra clarament la idea de procés, des de l'elaboració d'esborranys fins arribar a la versió definitiva. Al penúltim paràgraf escriu el següent:

De vegades guardo les diferents versions d'un article, pensant que un dia em serviran per il-lustrar als alumnes que això d'escriure és cosa difícil i que, doncs, també ells hi han de posar els cinc sentits. Però, novament, mai no he fet ús d'aquest material: la feina de preparació de classes és massa peremptòria i està massa lligada a les circumstàncies de cada curs o grup d'alumnes.

D'aquest fragment, com a mínim, se'n poden extreure tres idees clau: 1) que, com ja deien Pla o Espinàs, un escriptor expert reconeix que escriure no és fàcil; 2) que un bon escriptor fa versions prèvies, de manera que cal eradicar el prejudici segons el qual l'escriptor expert escriu a raig (Cassany 1999); i 3 ) que la tasca docent és summament complexa.

2 En l'àmbit de la llengua catalana, cal remarcar les investigacions en aquest camp (concretades a partir del constructe de seqüència didàctica) del Grup de Recerca en Ensenyament i Aprenentatge de Llengües (GREAL, UAB) i del Grup d'Investigació en Ensenyament de Llengües (GIEL, UV). I també, per la influència que ha generat en les recerques d'aquests grups, del Groupe de Recherche pour l'Analyse du Français Enseigné i Formation des Enseignants en Didactique du Français (GRAFE-FORENDIF). 


\section{Representacions de docents $i$ aprenents sobre el fet d'ensenyar i aprendre a escriure}

Per començar a desllorigar el repte d'ensenyar i aprendre a escriure, convindria que, com a docents, ens plantegéssim, com a punt de partida, les quatre preguntes següents: 1) Quina concepció tenim els ensenyants sobre l'ensenyament-aprenentatge de l'escriptura? 2) Com entenen els estudiants el fet d'escriure i d'aprendre a escriure? 3) Per què els estudiants haurien de voler aprendre a escriure (millor)? 4) Són les mateixes raons que tenim per ensenyar-los a escriure? Aquests interrogants han planat i continuen planant sobre la pràctica docent de qui escriu aquest article, i en les reflexions generades arran d'aquestes preguntes s'hi ha implicat, al llarg de diversos cursos acadèmics, l'alumnat del Màster d'Ensenyament del Català com a Primera i Segona Llengua (UB-UVic-UAB) ${ }^{3}$.

L'objectiu final és que l'aprenent sigui autònom davant l'activitat d'escriure i caldria assumir que la responsabilitat d'aconseguir aquest repte correspon tant al docent com a l'aprenent. Pel que fa a la perspectiva docent, a l'assignatura Aprofundiment en la Didàctica de les Habilitats Escrites de l'esmentat màster, els estudiants (futurs professors de llengua) es pregunten sobre les dificultats, els reptes i els prejudicis a l'entorn de l'ensenyament-aprenentatge de l'escriptura. A la Taula 1 es presenten cinc respostes, que il-lustren cinc grans tipus de preocupacions que manifesten els futurs docents ${ }^{4}$ :

Taula 1. Dificultats, reptes i prejudicis a l'entorn de l'E-A de l'escriptura

\begin{tabular}{|l|l|}
\hline a) No sé com motivar els estudiants perquè facin tasques d'escriptura. \\
\hline b) No tinc record de com em van ensenyar a escriure. \\
\hline c) Hem de "sacrificar" les hores de gramàtica a activitats d'escriptura? \\
\hline d) Corregeixo les faltes d'ortografia i de sintaxi però tinc la sensació que no serveix de res. \\
\hline e) Escriuen a casa perquè no podem perdre temps escrivint a l'aula. \\
\hline
\end{tabular}

Font: Respostes dels estudiants del màster al Fòrum virtual (curs 2014-2015)

L'enunciat a) No sé com motivar els estudiants perquè facin tasques d'escriptura, relatiu a la motivació, obre un ventall de reflexions que no es poden abordar en totes les seves dimensions en aquest article, però posa en relleu la presa de consciència de la motivació (Dörnyei 2001) com a element clau en l'ensenyament-aprenentatge de llengües. Procurar que l'estudiant s'adoni que pot aprendre a escriure (millor) i que noti els progressos que fa són aspectes motivacionals sobre els quals els docents tenen força a dir. Quant a l'enunciat b) No tinc record de com em van ensenyar a escriure, fa referència al docent com a aprenent i caldria connectar-lo amb els estudis sobre creences del professorat (Borg 2003) i l'impacte que té sobre la seva (futura) pràctica docent la manera com van aprendre a escriure i la manera com perceben l'escriptura i el seu aprenentatge. La dicotomia entre coneixement i ús (Myhill 2018) plana sobre l'enunciat c) Hem de "sacrificar" les hores de gramàtica a activitats d'escriptura?, que, junt amb l'enunciat d) Corregeixo les faltes d'ortografia i de sintaxi però tinc la sensació

3 Les dades que es presenten a partir d'aquest apartat procedeixen del material generat en el marc del Màster Oficial de Formació de Professorat de Català per a Persones Adultes (UB-UVic), al qual l'autora d'aquest article es va incorporar com a docent el curs 2007/2008, amb la impartició de l'assignatura Taller d'Escriptura. Des del curs 2013/2014 en una reorientació del màster (Màster d'Ensenyament del Català com a Primera i Segona Llengua, amb la incorporació de la UAB), hi ha impartit l'assignatura Aprofundiment en la Didàctica de les Habilitats Escrites. L'autora agraeix les aportacions dels estudiants de totes les edicions en què ha impartit docència fins al moment (curs 2018-2019).

4 Si bé els estudiants del màster no són, estrictament, docents, sinó futurs ensenyants de llengua, les seves respostes s'inclouen en la perspectiva docent (qui ensenya/ensenyarà a escriure), en contrast amb la perspectiva de l'aprenent (qui aprèn a escriure). Els estudiants del màster són aprenents de didàctica, però se situen en el rol d'ensenyants de llengua en el procés de construcció de la seva identitat com a docents. D'altra banda, entre els estudiants del màster també hi figuren docents (en actiu en el moment del màster o amb experiència prèvia). 
que no serveix de res, el qual s'orienta cap a l'eficàcia de la correcció (Adell 2009; Cassany 2016), esdevenen una de les preocupacions més tangibles expressades pels futurs ensenyants. Finalment, l'últim enunciat, e) Escriuen a casa perquè no podem perdre temps escrivint a l'au$l a$, evidencia un prejudici força extens, que consisteix a pensar que fer escriure a l'aula és perdre el temps. En realitat, si del que es tracta és d'ajudar l'aprenent durant el procés, aquesta bastida només és possible si l'estudiant escriu davant el docent, i l'espai per excel-lència per fer-ho és l'aula (Milian 2011).

Aquestes afirmacions, sorgides de la veu dels futurs ensenyants de llengua, haurien de ser el punt a partir del qual, pensant en el seu rol com a docents, comencessin a reconfigurar la seva relació amb l'escriptura i, per tant, amb el seu ensenyament. En aquest sentit, entenem que l'ensenyant també ha d'escriure i potser també hauria de parlar amb els seus estudiants sobre allò que escriu, perquè explicitar les dificultats que ha d'afrontar quan escriu el pot ajudar a entendre més bé els obstacles amb què topen els seus estudiants $i$, alhora, els estudiants es poden representar millor la complexitat de l'escriptura (Guasch 2004). En definitiva, difícilment concebríem un bon docent de llengües que no escrivís habitualment i que tampoc fos prou conscient de què implica el fet d'escriure.

De la mateixa manera que, com hem vist, l'ensenyant hauria de reflexionar sobre la seva relació amb l'escriptura, també caldria que ho fes qui adopta el rol d'aprenent. Per això, els estudiants del màster (futurs ensenyants) demanen a un alumne (generalment arran de la seva estada de pràctiques en un centre d'ensenyament de català per a adults) que respongui un qüestionari amb les tres preguntes següents, de les quals es presenten, a tall d'exemple, dues respostes per a cadascuna:

Taula 2. Qüestionari sobre la relació de l'aprenent amb l'escriptura

\begin{tabular}{|l|l|l|}
\hline $\begin{array}{l}\text { 1. Què és per a tu } \\
\text { l'escriptura? }\end{array}$ & $\begin{array}{l}\text { 2. En quines circumstàncies } \\
\text { escrius? }\end{array}$ & $\begin{array}{l}\text { 3. Amb quines dificultats et } \\
\text { trobes quan has d'escriure? }\end{array}$ \\
\hline $\begin{array}{l}\text { A la feina, és un mitjà que } \\
\text { tinc per comunicar-me amb } \\
\text { els altres i intercanviar infor- } \\
\text { mació. }\end{array}$ & $\begin{array}{l}\text { En circumstàncies professio- } \\
\text { nals, per correu electrònic i, } \\
\text { amb els amics, per Whats App. }\end{array}$ & $\begin{array}{l}\text { L'ortografia. I també parau- } \\
\text { les concretes que m'aniria } \\
\text { molt bé fer servir però que } \\
\text { no conec. }\end{array}$ \\
\hline $\begin{array}{l}\text { En l'àmbit personal, una ma- } \\
\text { nera d'ordenar-me les idees. }\end{array}$ & $\begin{array}{l}\text { Quan necessito ordenar } \\
\text { idees i recordar coses. I al } \\
\text { curs de català. }\end{array}$ & $\begin{array}{l}\text { Moltes vegades trasllado } \\
\text { directament el que penso al } \\
\text { paper i la profe em diu que el } \\
\text { text no s'entén. }\end{array}$ \\
\hline
\end{tabular}

Font: Respostes facilitades pels alumnes dels estudiants del màster (curs 2018-2019)

Sobre la primera pregunta, 1. Què és per a tu l'escriptura?, les dues respostes que es mostren posen en relleu, respectivament, dues de les característiques de l'escriptura: la dimensió social ("és un mitjà que tinc per comunicar-me") i l'epistèmica ("una manera d'ordenar-me les idees"). Les respostes a la segona pregunta, 2. En quines circumstàncies escrius?, van en la mateixa línia, amb la interessant incorporació de les dimensions professional ("en circumstàncies professionals, per correu electrònic") i didàctica ("al curs de català"). D'aquestes respostes cal subratllar el valor que l'aprenent adult atorga a l'escriptura, i aquest és un bon punt de partida per voler aprendre a escriure (millor), que és una de les reflexions que encetava aquest apartat.

Pel que fa a la tercera pregunta, 3. Amb quines dificultats et trobes quan has d'escriure?, la primera resposta il.lustra un prejudici, força extens, segons el qual l'ortografia és la principal preocupació a l'hora d'escriure. És un prejudici que convé superar de bell antuvi, perquè limitar els obstacles als aspectes lingüístics (i, encara més, als normatius) impedeix afrontar amb solvència l'ensenyament-aprenentatge de l'escriptura que, com s'ha comentat, sobretot 
hauria d'atendre aspectes cognitius i textuals. Els aspectes lingüístics (coneixement i domini del codi) són necessaris, és clar, però no pas suficients per reeixir en la composició escrita. Justament la segona resposta d'aquesta última pregunta té a veure amb el canvi de model cognitiu d'Scardamalia i Bereiter (1992) al qual ja ens hem referit, i que implica passar de "dir" a "transformar" el coneixement. Certament, la plasmació del coneixement que finalment es presenta al lector és de caràcter lingüístic (a través de la llengua escrita), però el procés de transformació del text pensat al text realitzat (Gallego, García i Rodríguez 2013, p. 23-27) requereix una sèrie d'operacions que van més enllà de la llengua.

La confluència entre les respostes dels futurs docents i les dels aprenents ens poden ajudar a orientar l'ensenyament-aprenentatge de l'escriptura. Sovint, com a ensenyants de llengua, ens preguntem per on podem començar a descabdellar la troca. En primer lloc, pot ser interessant conèixer a fons la relació que els nostres aprenents tenen amb l'escriptura, és a dir, no es tracta només de diagnosticar el seu estat d'escriptura, sinó també de saber com perceben l'escriptura en la seva vida i fins a quin punt voldrien millorar aquesta habilitat. D'altra banda, per conèixer com escriuen no n'hi ha prou a analitzar un text que hagin produït, sinó que convé compartir el procés d'escriptura des del primer moment, o sigui, des de la planificació fins a la revisió. I, finalment, com ja s'ha avançat, hauríem d'atendre prioritàriament aspectes cognitius i textuals (i no posar únicament el focus en els lingüístics). $O$, dit d'una altra manera, caldria plantejar els aspectes lingüístics al servei dels textuals.

\section{El problema retòric en l'ensenyament-aprenentatge de la composició escrita}

Si els principis que s'han anat desgranant a les seccions anteriors són assumits i compartits, tant per docents com per aprenents, es poden dissenyar situacions didàctiques per anar superant els obstacles que van apareixent en el procés d'ensenyament-aprenentatge de l'escriptura. En aquest apartat ens centrarem en el plantejament de la tasca d'escriptura i en la conveniència que l'aprenent es pugui representar el problema retòric, és a dir, el context situacional a partir del qual hauria d'afrontar la producció d'un text (Benítez 2004). D'acord amb el que s'ha comentat més amunt, per acompanyar l'aprenent en el procés de "dir" a "transformar" el coneixement (Scardamalia i Bereiter 1992), cal que l'alumne tingui present no només què vol dir (problema de contingut), sinó també -i sobretot-, com ho vol dir (problema retòric). Es tracta que el docent dissenyi abans de tot el problema retòric que desencadenarà la necessitat d'escriptura d'un text, de manera que l'aprenent es figuri la situació comunicativa i disposi de tota la informació necessària per començar a escriure: per a qui escriu? Per a què? Quin és el seu rol com a escriptor? Quin és el context en el qual s'insereix el text que vol escriure?

Que l'alumne tingui a la seva disposició tota la informació que necessita no vol dir que, d'entrada, ja sàpiga com procedir, però probablement no podrà començar a prendre decisions cognitives, textuals i lingüístiques (o no podrà prendre-les amb prou coneixement de causa) si no ha comprès d'on parteix i cap a on ha d'anar. Camps (2004, p. 35) il.lustra aquesta idea amb una analogia entre el plantejament d'un problema retòric i d'un problema matemàtic:
¡Menudo problema tan complejo, escribir un texto! Todos sabemos que para resolver un problema es necesario que esté bien planteado y hay que entender los términos del plan- teamiento, lo cual no querrá decir saber ya de entrada todo el camino que se va a seguir. A menudo surgen contratiempos que nos hacen replantear una parte o todo el problema. Para resolverlo también hay que conocer procedimientos para superar contratiempos.

Així doncs, com a docents, la primera responsabilitat que potser caldria assumir consisteix a dissenyar una bona situació retòrica i, un cop plantejada, anticipar quins contratemps (obstacles, dificultats, limitacions) poden sorgir, com també preveure de quina naturalesa són: l'aprenent entén la consigna que se li planteja? Quina mena de coneixements textuals i lingüís- 
tics cal mobilitzar per portar a terme la tasca d'escriptura? L'aprenent els pot activar? Quins? Quins no? Quins li cal aprendre? Com els hi podem ensenyar? Com els seqüenciem?

El problema retòric es pot manifestar de moltes maneres i s'associa a la fase de la planificació. A banda de l'analogia a la qual fa referència Camps, el plantejament d'una situació d'escriptura també pot expressar-se a través d'altres exemples de la vida quotidiana que, sovint, interpel.len d'una manera més directa els nostres aprenents. Imaginem-nos una hipotètica situació en la qual una colla d'amics ens conviden a fer una sortida a la muntanya. El missatge de WhatsApp que rebem és el següent: "Quedada demà a 8.00am al camp de futbol. Porta aigua i menjar". Tot i que la primera part de la consigna és clara (punt de sortida, lloc de trobada), no deixa de ser incompleta i ens genera un munt de preguntes: on anem, exactament? Quins companys de ruta hi haurà? Qui farà de guia? Quin és el calçat més adequat? Quina és la previsió meteorològica? Quanta aigua i quant menjar cal portar? Quina ruta farem? Estic preparada per fer aquesta ruta? Quant durarà l'excursió? Hi ha molt desnivell? Algú portarà el GPS? Etc.

Massa sovint, les consignes que plantegem per a portar a terme una tasca d'escriptura també són incompletes i impedeixen a l'aprenent disposar de tota la informació que, a priori, necessita per representar-se què li estem demanant exactament. Per a què escric? Per a qui haig d'escriure? Quin gènere és el més adequat per resoldre el problema retòric? Quina extensió ha de tenir el meu text? Quant temps tinc per escriure? He d'escriure a l'aula o puc fer-ho a casa? De quins recursos disposo? Quin acompanyament tindré? I, finalment, dues preguntes clau, que també caldria que tot estudiant es formulés en una situació d'ensenyament-aprenentatge: què se suposa que aprenc fent aquesta tasca? I com s'avaluarà el meu escrit? Així doncs, el primer que hauria de fer el docent és saber plantejar situacions retòriques per ajudar l'aprenent a aferrar-se a un bon punt de partida, és a dir, per emprendre el procés d'escriptura, talment el guia de muntanya que ajuda el principiant a preparar-se per a fer un cim. Entenem així la figura del docent com a guia, que acompanya l'aprenent des del principi fins al final d'aquest viatge, amb l'horitzó que, en un futur més o menys proper, qui escriu (qui fa senderisme) pugui ser prou autònom per avançar sense ajut.

Als estudiants del màster se'ls proposa, com a activitat avaluable, que demanin a un aprenent que escrigui un text a partir d'una situació retòrica dissenyada ad hoc (és a dir, per ells mateixos i per a l'aprenent en concret). Un cop l'aprenent ha elaborat el text, l'estudiant de màster (futur docent) l'ha d'analitzar des del punt de vista de les tres propietats textuals $i$, a partir d'aquesta anàlisi, proposar una millora que permeti a l'aprenent resoldre algun aspecte concret de la seva producció escrita. L'activitat avaluable parteix dels objectius i del guió següents ${ }^{5}$ :

Taula 3. Objectius i estructura de l'activitat avaluable del màster

\section{Objectius}

1. Saber dissenyar una situació retòrica ad hoc a partir dels interessos i característiques de l'aprenent/a.

2. Saber analitzar una producció escrita a partir de les propietats textuals (adequació, coherència i cohesió).

3. Aprendre a considerar l'error de l'aprenent/a com a oportunitat d'aprenentatge.

4. Relacionar la tasca amb les lectures i el material de l'assignatura.

5. Reflexionar sobre els aprenentatges adquirits (sobre l'execució de la tasca i sobre l'ensenyament-aprenentatge de l'escriptura).

5 En l'article no es pot desenvolupar tot el dispositiu didàctic, però en aquest apartat i els següents es despleguen els objectius 1 i 5 i els punts 1-2-7 de l'estructura l'activitat avaluable, que són els que se centren en el plantejament de les tasques d'escriptura. 


\section{Estructura de l'activitat avaluable}

1. Perfil de l'aprenent/a - Descripció de les característiques de l'aprenent/a que tenen o poden tenir interès per al disseny de la situació retòrica $i$, en general, de la tasca d'escriptura (p. e. L1 de l'aprenent o informació obtinguda mitjançant el qüestionari sobre la relació de l'aprenent amb l'escriptura).

2. Descripció de la consigna - Explicitació i justificació de la situació retòrica dissenyada que ha de desencadenar la demanda d'escriptura.

3. Text produït per l'aprenent/a - Reproducció del text tal com l'aprenent l'ha escrit (si escau, es pot transcriure per facilitar-ne l'anàlisi).

4. Anàlisi dels encerts vinculats a les tres propietats textuals (adequació, coherència i cohesió).

5. Anàlisi dels errors (aspectes millorables) vinculats a les tres propietats textuals.

6. Proposta de millora d'un dels aspectes detectats en el punt anterior.

7. Reflexions finals - Sobre la utilitat i l'interès de la proposta didàctica, les dificultats sorgides durant el disseny (elaboració de la situació retòrica) i l'execució de la tasca (anàlisi de la producció escrita), els coneixements adquirits o reformulats a l'entorn de l'ensenyament i l'aprenentatge de l'escriptura, etc.

8. Referències bibliogràtiques.

Font: Enunciat de l'activitat avaluable de l'assignatura

Aprofundiment en la Didàctica de les Habilitats Escrites.

Tot seguit, es presenten i justifiquen dos exemples de situació retòrica dissenyades per dos estudiants del màster. El primer exemple (Taula 4) il.lustra una situació retòrica original i alhora exigent, en la qual l'aprenent a qui s'adreça la consigna es pot representar amb exactitud quin context situacional embolcalla la tasca d'escriptura.

\section{Taula 4. Exemple 1 de situació retòrica}

D'aquí a dos mesos el teu pare fa 50 anys i li vols preparar una festa sorpresa perquè recordi aquest dia com un de molt especial.

Escriu un correu electrònic a la teva família (mare, germans, tiets i avis) per informar-los del que vols organitzar i el perquè. Has d'explicar-los què has pensat (planificació del dia, horaris i mobilitat). També has d'escriure quin serà el pressupost, quin dia es farà la celebració i sobretot necessites saber qui vindrà per poder organitzar la festa amb temps per si has de fer algun canvi.

Has d'escriure un correu electrònic perquè estàs estudiant a l'estranger i les trucades et sortirien massa cares.

Nota: Alguns familiars no s'avenen gaire entre ells però vols que vinguin perquè al teu pare li farà molta il.lusió. Recorda també que els avis no tenen correu electrònic.

Font: Punt 2 de l'activitat avaluable d'una estudiant del màster. Curs 2015-2016.

D'acord amb el contingut de la Taula 4, l'aprenent, abans de posar-se a escriure, és a dir, durant la fase de la planificació del text, ha de comprendre i processar la informació de què disposa. En aquest sentit, convé recordar com d'important és que, a priori, entengui la consigna (lectura i escriptura són processos dialògics; Pérez 2007; Shanahan 2019) i, a partir d'aquí, mobilitzi els seus coneixements, tant cognitius com textuals. Entre d'altres, ha de pensar sobre aspectes vinculats al tema, al gènere (correu electrònic), al registre (informal), a la informació que ha de contenir el missatge de correu electrònic (tant la que ha d'aportar com a emissor com la que ha de sol-licitar com a receptor), als destinataris (directes i indirectes, d'acord amb la nota final de la consigna), etc. La consigna fins i tot explicita la raó per la qual cal que l'aprenent escrigui un correu electrònic i no pas que resolgui la demanda comunicativa a través d'un altre canal (d'entrada, la trucada semblaria més fàcil tenint en compte el context). 
El segon exemple de situació retòrica (Taula 5) descriu una consigna més freqüent que la primera (en el sentit que és un enunciat semblant al que es pot trobar en materials didàctics publicats), però serveix per il-lustrar les informacions que aporta perquè l'aprenent pugui representar-se per a qui i què ha d'escriure:

\section{Taula 5. Exemple 2 de situació retòrica}

Una revista de viatges té una secció de recomanacions dels lectors. Cada mes publiquen els consells o suggeriments d'alguns viatgers a partir de les seues últimes experiències. L'any passat vares fer un viatge llarg en què descobrires indrets gairebé secrets que vols compartir amb altres persones, i has decidit que aquesta revista és un bon lloc on fer-ho.

Tens entre 300 i 500 paraules per esmentar els llocs que visitares i la recomanació o consell concret que vols fer als lectors. Tengues en compte que ha de ser útil als potencials viatgers: per exemple, si parles d'un lloc has d'explicar com arribar-hi, o com a mínim, on trobar algú que en doni indicacions vàlides; si parles d'una activitat hauries d'especificar-ne els preus i els horaris, i si parles d'una experiència més personal has de proposar una actitud que propiciii aquest tipus d'actes. Recorda, sobretot, que els teus destinataris són viatgers que busquen inspiració.

Font: Punt 2 de l'activitat avaluable d'un estudiant del màster. Curs 2016-2017.

En l'exemple anterior, l'aprenenta ha de posar-se en el lloc d'una persona que viatja habitualment (l'estudiant del màster crea aquesta situació retòrica arran de conèixer-ne el perfil -punt 1 de l'estructura de l'activitat avaluable). La descripció de la consigna permet recopilar les següents dades: l'objectiu (compartir l'últim viatge que ha fet l'aprenenta), el propòsit concret (descriure els indrets, fer recomanacions pràctiques, aportar informació útil), els destinataris ("potencials viatgers", "viatgers que busquen inspiració"), l'extensió ("entre 300 i 500 paraules") i altres informacions, amb exemples concrets, tant organitzatives (com arribar als indrets, preus i horaris de les activitats proposades) com experiencials ("proposar una actitud que propiciï aquest tipus d'actes").

Les dues situacions retòriques anteriors il-lustren fins a quin punt les tasques d'ensenyament-aprenentatge de l'escriptura haurien de ser autèntiques o, com a mínim, al màxim de versemblants possibles (Boscolo i Gelati 2019; Castelló, 2008; Martín Peris, 2001). Difícilment l'aprenent es motivarà davant d'activitats d'escriptura inconcretes, artificioses o allunyades de la seva realitat (llevat del cas, és clar, que explorem expressament amb exercicis d'estil -Queneau 1989- o, per exemple, amb propostes d'escriptura extensiva -Cassany 1997). En tot cas, una activitat mal plantejada des del punt de vista de la situació retòrica implicarà dèficits en la primera fase de l'activitat d'escriptura (la planificació), que probablement s'arrossegaran al llarg de tot el procés i en condicionaran la qualitat del producte final.

\section{Reflexions sobre aprendre a ensenyar a escriure a partir de la situació retòrica}

En aquest apartat es presenten quatre fragments de les reflexions que els futurs docents fan sobre l'interès didàctic de l'activitat avaluable. Aquestes reflexions se centren, sobretot, en el plantejament de les tasques d'escriptura i en la importància de dissenyar una bona situació retòrica (veg. Taula 3, punt 7) i es relacionen, a manera de discussió, amb els referents teòrics d'aquest article (apartat 2).

Taula 6. Fragments extrets de les reflexions finals de l'activitat avaluable

Fragment 1:

"Cal acostumar l'aprenent a prendre consciència que escriure significa comunicar alguna cosa a algú en un context determinat” (M.G., curs 2013/2014) 


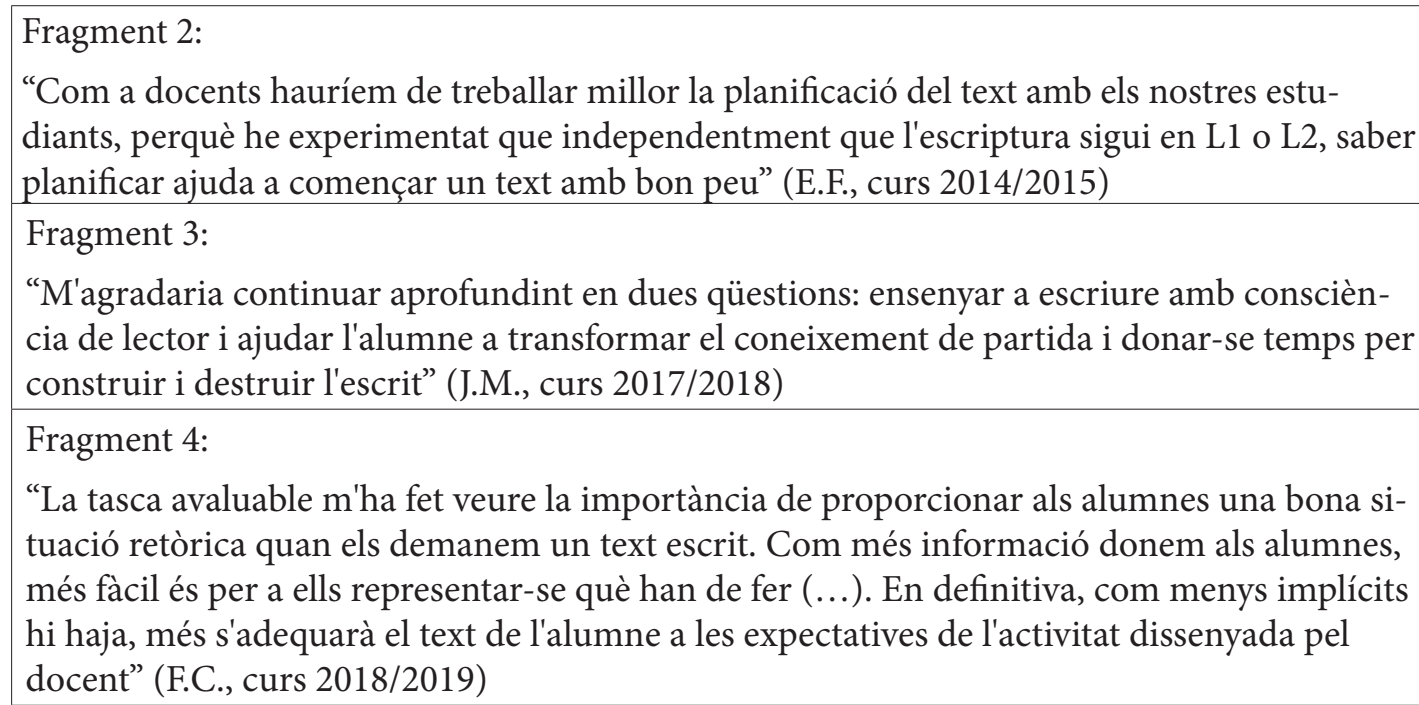

Font: Respostes facilitades pels alumnes dels estudiants del Màster (diversos cursos acadèmics)

El fragment 1 suggereix la necessitat que els docents ajudin a incorporar en l'imaginari de l'aprenent la importància de la situació retòrica en qualsevol situació d'escriptura. Convindria que qui escrivís compartís la idea que l'escriptura és una activitat dialèctica (Camps 2004), l'objectiu de la qual és, tal com manifesta l'estudiant, "comunicar alguna cosa a algú en un context determinat". És a dir, "prendre consciència" que sempre hi ha un destinatari (Carlino 2004a) i una situació comunicativa que emmarca la producció de l'escrit (Benítez 2004).

Quant al fragment 2, l'estudiant reivindica que en situacions d'ensenyament-aprenentatge s'atengui més la primera fase del procés d'escriptura, perquè considera que "saber planificar ajuda a començar un text amb bon peu”. Si bé les tres fases del procés d'escriptura són recursives, caldria que el seu ensenyament fos successiu, una fase darrere l'altra, perquè amb la planificació es posen els fonaments per anar bastint el text (McKeown i FitzPatrick 2019). Al fragment també es corrobora, a partir de la pròpia experiència, que les estratègies per aprendre a planificar un text són independents de la llengua en què s'escriu, reflexió summament interessant quan s'ensenya a escriure en segones llengües (Kroll 2003), atès que la recerca demostra que certes estratègies d'escriptura en L1 són transferibles a l'escriptura en L2 (Krapels 1990).

El fragment 3 insisteix en la necessitat que el docent sigui capaç d'ajudar l'aprenent per tal que pugui superar dos reptes vinculats al procés de composició escrita: en primer lloc, el repte d'aprendre a escriure "amb consciència de lector" (idea ja apuntada al fragment 1); i, en segon lloc, el repte de passar del model de "dir" al model de "transformar" el coneixement (Scardamalia i Bereiter 1992). De fet, tots dos reptes en realitat es fusionen en un, ja que el pas d'un model a l'altre implica, justament, que durant el procés d'escriptura es prenguin decisions tenint en compte el destinatari. La idea de "construir i destruir l'escrit" remet, també, a la recursivitat de les fases d'escriptura i al fet que un bon text és fruit de diverses versions.

Finalment, el quart fragment apel.la als beneficis didàctics de dissenyar una bona situació retòrica. Després de realitzar l'activitat avaluable, l'estudiant s'adona que plantejar propostes d'escriptura amb un punt de partida concret i explícit ("com més informació donem als alumnes", "com menys implícits hi haja") facilita a l'aprenent l'execució de la producció escrita i, alhora, apropa el text "a les expectatives de l'activitat dissenyada pel docent". Aquesta última idea connecta amb un altre aspecte que, com s'ha recollit a la Taula 1, també preocupa (i molt) als futurs docents: la correcció i l'avaluació de l'escriptura. Tot i que no ens hi podem estendre, apuntem que una bona situació retòrica facilita la confluència entre les expectatives del docent i les de l'aprenent en relació amb el producte final, i que compartir aquest horitzó repercuteix positivament en l'avaluació (Ribas 1997 i 2001; Cassany 1993; Carlino 2004b; Wilson 2019). 


\section{Conclusions}

En aquest article s'ha partit de la complexitat de l'escriptura per abordar, des de l'assumpció d'aquesta premissa, el també complex procés d'ensenyar i aprendre a escriure. Ja sigui en primeres o en segones llengües, les evidències que aporta la recerca ens ajuden a plantejar l'ensenyament-aprenentatge de la composició escrita des de l'atenció al procés, amb la necessària implicació tant de docents com d'aprenents. En aquest propòsit, cadascú parteix de la pròpia representació sobre l'escriptura i sobre el fet d'ensenyar (docent) o d'aprendre (alumne) a escriure, però el repte és compartit i convé que les expectatives conflueixin i que els obstacles amb què topen els aprenents durant aquest procés s'acompanyin, en paral.lel, d'estratègies didàctiques per aconseguir superar-los. D'acord amb Milian (2011, p. 105), "hem d'admetre que escriure representa no solament un producte, sinó també un procés recursiu i un participant actiu en aquest procés guiat per una intenció". Des del punt de vista didàctic, l'explicitació de l'ensenyament d'estratègies d'escriptura hauria de començar amb el disseny d'una bona situació retòrica, que permetés a l'aprenent afrontar el repte amb la motivació, les eines, els recursos i també amb la presa de consciència del que ha d'anar aprenent per avançar en el procés. L'objectiu final és, manllevant les paraules de Guasch (2001), aconseguir "el control conscient de l'escriptor per adaptar la informació elaborada i la seva forma lingüística a les demandes d'un espai retòric determinat" (p. 12).

En els apartats precedents s'han presentat les idees clau sobre l'ensenyament-aprenentatge de l'escriptura i s'ha mostrat un dispositiu didàctic en el marc d'una formació postuniversitària per a futurs docents de llengua. A partir de la pràctica docent portada a terme al llarg de diversos cursos acadèmics, s'han mostrat les representacions que estudiants del màster (futurs docents), per una banda, i aprenents, per l'altra, tenen sobre l'escriptura i sobre el fet d'ensenyar i aprendre a escriure. Aquestes representacions ajuden a comprendre quina és la línia de sortida de cada agent implicat en el procés i contribueixen a ajustar les estratègies d'ensenyament-aprenentatge de l'escriptura. En concret, s'ha mostrat una proposta didàctica en el qual s'ha posat èmfasi en el disseny de la situació retòrica, en tant que element generador de la tasca d'escriptura. Finalment, també s'han posat en comú algunes reflexions dels futurs docents sobre la importància de la planificació, entesa com una fase cabdal per al desencadenament de la resta de decisions del procés d'escriptura.

Per acabar i reprenent l'analogia del docent com a guia de muntanya, l'objectiu no hauria de ser que l'excursionista novell assolís un cim al primer intent. Al contrari, convindria proposar-se que qui s'està introduint en aquesta pràctica tingués interès per cultivar-la, que no perdés les forces només d'iniciar (o d'acabar) la primera excursió i que, amb l'acompanyament just i adequat, superés, pas a pas, els esculls muntanyencs i acabés assolint el pic que s'ha marcat. Tornant a l'escriptura, al principi de l'article subratllàvem com de poderós és el domini d'aquesta habilitat a l'hora de sentir-se partícip de la comunitat. El repte d'ensenyar i aprendre a escriure, doncs, consisteix a explorar totes les oportunitats didàctiques que siguin al nostre abast per fer possible aquesta participació (Casas 2020). En aquest sentit, l'article s'ha centrat en un aspecte concret d'aquest repte (el plantejament de les tasques d'escriptura), reivindicant la corresponsabilitat de docents i aprenents en el procés d'ensenyament i aprenentatge de la composició escrita.

\section{Referències bibliogràfiques}

Adell, P. (2009). La correcció i l'avaluació de l'escrit segons la veu del professorat. Articles de Didàctica de la Llengua i la Literatura, 47, 73-84.

Bazerman, C. (2009). Genre and cognitive development: beyond writing to learn. Dins C. Bazerman, A. Bonini i D. Figueiredo (eds.), Genre in a changing word (Perspectives on writing). WAC Clearinghouse. Consultat des de https://wac.colostate.edu/docs/books/genre/genre.pdf 
Bazerman, C. (2016). What do sociocultural studies of writing tell us about learning to write? Dins C.A. MacCarthur, S. Graham i J. Fitzgerald (eds.), Handbook of writing research (p.11-23). Guilford.

Benítez, R. (2004). La situación retórica: Su importancia en el aprendizaje y en la enseñanza de la producción escrita. Revista signos, 33 (48), 49-67. doi: 10.4067/S0718-09342000004800005

Borg, S. (2003). Teacher cognition in Language teaching: A review of research on what Language teachers think, know, believe and do. Language Teaching, 36(2), 81-109.

Boscolo, J. i Gelati, C. (2019). Motivating writers. Dins S. Graham, Ch. A. McArthur i M. Herbert (eds.), Best practices in writing instruction (p. 51-78). The Guildford Press.

Bronckart, J.P. (2008). ¿Genres de textes, types de discours et “degrés” de langue? Textos, 13(1), 1-96. Camps, A. (2004). Motivos para escribir. Dins A. Camps (comp.), La composición escrita (de 3 a 16 años) (p. 27-38). Graó.

Camps, A. (2017). Escriure i aprendre a escriure, dues activitats que s'encreuen. Bases per a l'ensenyament de l'escriptura a l'educació obligatòria (II). Articles de didàctica de la llengua i la literatura, 72, 39-45.

Camps, A. (comp.) (2003). Seqüències didàctiques per aprendre a escriure. Graó.

Camps, A. (comp.) (2004). La composición escrita (de 3 a 16 años). Graó.

Camps, A., Fontich, X. i Milian, M. (en premsa). Los géneros de aprendizaje en la actividad académica. Dins Castelló, M. i Castells, N. (eds.), Escribir en la universidad española: investigación y propuestas de intervención (p. 1-25). Red RIEA-EA.

Carlino, P. (2004a). El proceso de escritura académica. Cuatro dificultades en la enseñanza universitaria. Educere, 26, 321-327.

Carlino, P. (2004b). La distancia que separa la evaluación escrita frecuente de la deseable. Acción pedagógica, 13(1), 8-17.

Casas, M. (2020). Aprender a escribir una autobiografía lingüística. Un ejemplo de escritura reflexiva y metacognitiva en la formación inicial de maestros. Indagatio Didactica, 12 (2), 5571. doi.org/10.34624/id.v12i2.17493

Cassany, D. (1993). Reparar l'escriptura. Didàctica de la correcció de l'escrit. Graó.

Cassany, D. (1997). L'escriptura extensiva. Com desenvolupar hàbits de redacció. Dins G. Pujals, E. Sanahuja (comp.), Saber de lletra V. Recursos i materials de suport per a la Reforma a l'Àrea de Llenguatge (p.21-45). Departament de Didàctica de la Llengua i la Literatura, Universitat de Barcelona.

Cassany, D. (1999). Construir l'escriptura. Empúries.

Cassany, D. (2016). La correcció dels escrits. Del núvol al vermell. Articles de Didàctica de la llengua i de la literatura, 68, 38-43.

Castelló, M. (2008). Escribir para aprender: estrategias para transformar el conocimiento. Aula de Innovación educativa, 175, 15-21.

Castelló, M. (2014). Los retos actuales de la alfabetización académica: estado de la cuestión y últimas investigaciones. Enunciación, 19(2), 346-365. doi: 10.14483/10.14483/udistrital.jour. enunc.2014.2.a13

Cummins, J. (1979) Linguistic interdependence and the educational development of bilingual children. Review of Educational Research, 49(2), 222-251.

Cummins, J. (2005). La hipótesis de la interdependencia 25 años después: la investigación actual y sus implicaciones para la educación bilingüe. Dins D. Lasagabaster i J.M. Sierra (eds.), Multilingüismo y multiculturalismo en la escuela (p. 113-132). Horsori. 
Direcció General de Política Lingüística i Institut d'Estadística de Catalunya (2019). Els usos lingüistics de la població de Catalunya. Resultats de l'Enquesta d'usos lingüístics de la població 2018. Generalitat de Catalunya. Consultat des de https://lengua.gencat.cat/web/.content/documents/dadesestudis/altres/arxius/dossier-eulp-2018.pdf

Dolz-Mestre, J. i Abouzaid, M. (2015). Pluralité des genres et singularité du texte: Tensions constitutives de la didactique des langues. Forumlecture.Ch, 2. Consultat des de https://archive-ouverte.unige.ch/unige:76731

Dörnyei, Z. (2001). Motivational strategies in the language classroom. Cambridge University Press. Espinàs, J.M. (2013). Una vida articulada. La Campana.

Flower, L. i Hayes, J. (1980). The dynamics of composing: making plans and juggling constraints. Dins L.W. Gregg i E.R. Steinberg (eds.), Cognitive Processes in Writing (p. 3-30). Routledge. Gallego, J.L.; García, A i Rodríguez, A. (2013). Cómo escriben los futuros docentes. Estrategias para la mejora. Aljibe.

García, J. i Fidalgo, R. (2003). Diferencias en la conciencia de los procesos psicológicos de la escritura: mecánicos frente a sustantivos y otros. Psicothema, 15(1), 41-48. Consultat des de https://www.redalyc.org/pdf/727/72715107.pdf

Graham, S. i Harris, K. (2016). A Path to Better Writing. Evidence-Based Practices in the Classroom. The Reading Teacher, 69(4), 359-365. doi:10.1002/trtr.1432

Graham, S., McArthur, Ch. A. i Herbert, M. (eds.) (2019). Best practices in writing instruction. The Guildford Press.

Guasch, O. (2001). L'escriptura en segones llengües. Graó.

Guasch, O. (2004). Hablar para escribir. Dins A. Camps (comp.), La composición escrita (de 3 a 16 años) (p. 39-46). Graó.

Hayes, J.R. i Flower, L. (1981). Writing as a problem solving. A visible language, 14, 388-399.

Klein, P.D. i Boscolo, P. (2016). Trends in research on writing as a learning activity. Journal of Writing Research, 7(3), 311- 50. doi: 10.17239/jowr-2016.07.03.01

Krapels, A.R. (1990). An overview of second language writing process research. Dins Kroll, B. (ed.), Second language Writing (p. 37-56). Cambridge University Press.

Kroll, B. (coord) (2003). Exploring the dynamics of second language writing. Cambridge University Press.

Martín Peris, E. (2001). Què vol dir treballar a classe amb tasques comunicatives? (i II). Llengua $i$ ús: revista tècnica de política lingüística, 2001, 22, 55-60. Consultat des de https://www.raco.cat/index.php/LlenguaUs/article/view/127885

Mas, A. (2018). El valencià segons l'enquesta del SIES de 2015. Treballs de Sociolingüística Catalana, 28, 127-145. doi: 10.2436/20.2504.01.147

McKeown, D i FitzPatrick, E. (2019). Planning. Dins S. Graham, Ch. A. McArthur i M. Herbert (eds.), Best practices in writing instruction (pp. 211-239). New York/London: The Guildford Press.

Milian, M. (2011). La composició escrita. Com ensenyem a escriure, com n'aprenen els alumnes? Articles de Didàctica de la llengua i de la literatura, 54, 104-113.

Myhill, D. (2018). Grammar as a meaning-making resource for improving writing. L1-Educational Studies in Language and Literature, 18, 1-21. doi:10.17239/L1ESLL-2018.18.04.04

Navarro, F. (2019). Aportes para una didáctica de la escritura académica basada en géneros discursivos. D.E.L.T.A., Documentação de Estudos em Lingüística Teórica e Aplicada, 35-2, 1-32. doi:10.1590/1678-460x2019350201.

Olson, D.R. (1995). La cultura escrita como actividad metalingüística. Dins D.R. Olson i N. 
Torrance (comps.), Cultura escrita y oralidad (p. 333-357). Gedisa.

Pérez, J. (2007). La lectura y la escritura: Procesos dialógicos y recursivos. Sapiens. Revista Universitaria de Investigación, 8(1), 99-109.

Pla, J. (1979). Notes del capvesprol. Obra Completa, 35. Destino.

Queneau, R. (1989). Exercicis d'estil. Quaderns Crema.

Ribas, T. (1997). L'avaluació formativa en el procés d'escriptura: un instrument per a l'aprenentatge. Dins T. Ribas, T. (coord.), L'avaluació formativa a l'àrea de llengua (p. 131-156). Graó.

Ribas, T. (2001). Què pot aportar l'avaluació formativa a l'ensenyament i aprenentatge de l'escriptura. Articles de Didàctica de la Llengua i de la Literatura, 25, 31-41.

Scardamalia, M. i Bereiter, C. (1992). Two explicative models for the processes of written composition. Infancia y aprendizaje, 58, 43-64.

Schneuwly, B. (1988). La conception vygostksyenne du langage écrit. Études de Linguistique Apliquée, 73, 107-117.

Shanahan, T. (2019). Reading-Writing connections. Dins S. Graham, Ch. A. McArthur i M. Herbert (eds), Best practices in writing instruction (pp. 309-332). New York/London: The Guildford Press.

Silva, T. (1990). Second language composition instruction: developments, issues and directions in ESL. Dins Kroll, B. (ed.), Second language Writing (p. 11-23). Cambridge University Press.

Solà, J. (1998, febrer 19). Com faig un article de l'Avui. Avui.

Solé, I. (2012). La competència lectora: una clau per a l'aprenentatge. Debats d'Educació, 24. Barcelona: Fundació Bofill. Consultat des de https://fbofill.cat/sites/default/files/548.pdf

Wilson, J. (2019). Assessing writing. Dins S. Graham, Ch. A. McArthur i M. Herbert (eds.), Best practices in writing instruction (p. 333-360). The Guildford Press. 
